\title{
Alkylverdazyls as a Source of Alkyl Radicals for Light-triggered Cancer Cell Death
}

Darya E. Votkina, ${ }^{\text {a }}$ Evgenii V. Plotnikov, ${ }^{\text {a }}$ Pavel V. Petunin, ${ }^{* a}$ Elizaveta S. Berdinskaya, ${ }^{a}$ Maria

S. Tretyakova, ${ }^{\mathrm{a}}$ Gérard Audran, ${ }^{\mathrm{b}}$ Sylvain R.A. Marque, ${ }^{\mathrm{b}}$ Pavel S. Postnikov ${ }^{\mathrm{a}, \mathrm{c}_{*}}$

${ }^{a}$ Research School of Chemistry \& Applied Biomedical Sciences, Tomsk Polytechnic University, 30 Lenin Avenue, Tomsk, 634050, Russia.

E-mail: petuninpavel@tpu.ru; postnikov@tpu.ru

b Aix Marseille University, CNRS, ICR, UMR 7273, Case 551, Avenue Escadrille NormandieNiemen, 13397 Marseille Cedex 20, France.

c Department of Solid-State Engineering, University of Chemistry and Technology, 16628 Prague, Czech Republic

\section{Table of Content}

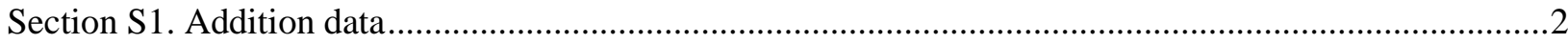

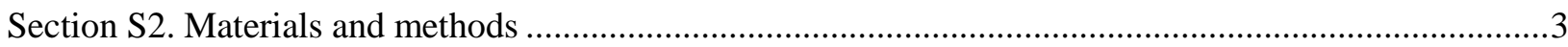

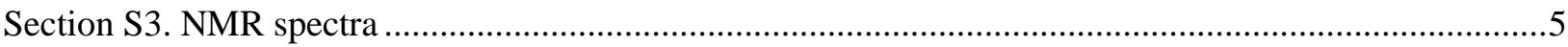

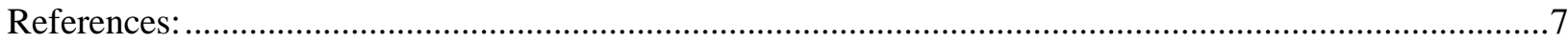




\section{Section S1. Addition data}

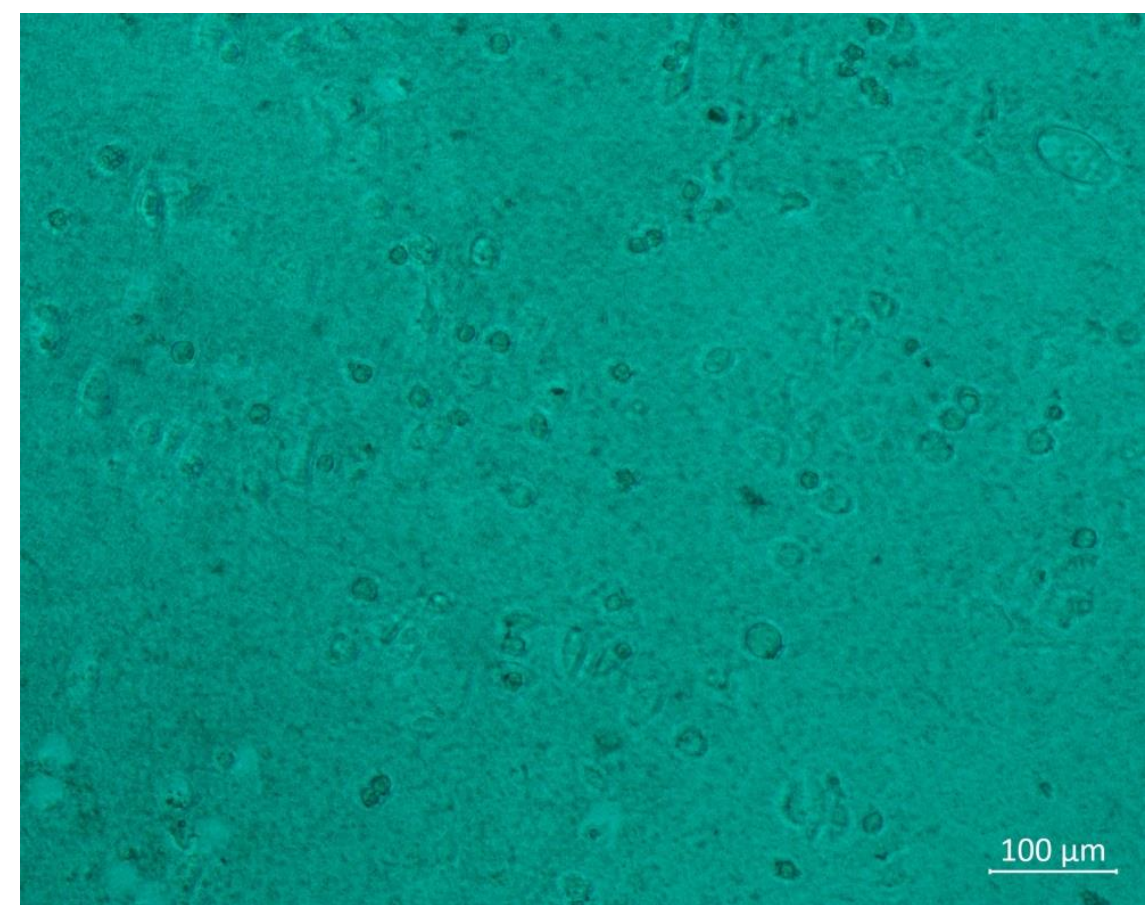

Fig. S1.1. Highly aggregated crystals of AlkVZ 1 in $65 \mu \mathrm{M}$ concentration in well.

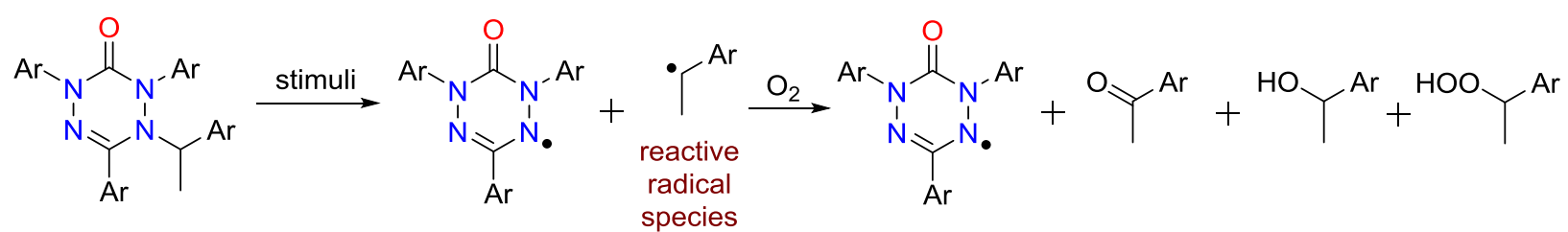

Fig. S1.2. Principle of side product generation via the scavenging of the released alkyl radical with $\mathrm{O}_{2}$.

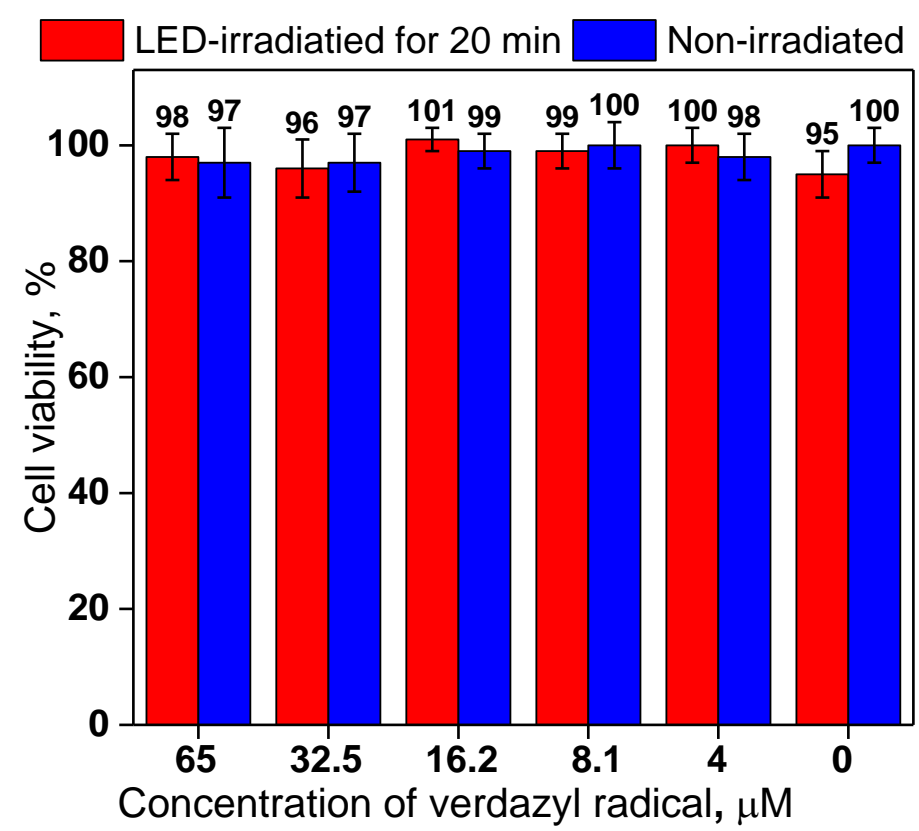

Fig. S1.3. Dependence of viability vs. concentration of verdazyl radical which was initial compound for synthesis of AlkVZ 2 tested on MCF-7 cells. 


\section{Section S2. Materials and methods}

\section{General}

All organic reagents and solvents were purchased from commercial suppliers (Sigma-Aldrich) and were used as received. ${ }^{1} \mathrm{H}$ and ${ }^{13} \mathrm{C}$ NMR spectra were recorded on Bruker Advance III HD (400 MHz) instrument. Absorption spectra were registered on the Agilent Technologies Cary 60 UV-Vis spectrophotometer. Melting points were determined on the Mettler Toledo Melting point system MP50. Elemental analysis was performed using a Euro EA 3000 (EuroVector).

\section{Preparation of alkylated verdazyls}

Alkylated verdazyl 1 was prepared using previously reported method [S1] and AlkVZ 2 was synthesized by the same method:

To a solution of $\mathrm{Cu}(153 \mathrm{mg}, 2.4 \mathrm{mmol}), \mathrm{CuBr}(172 \mathrm{mg}, 1.2 \mathrm{mmol})$, PMDETA (N,N,N',N",N"pentamethyldiethylenetriamine) $(251 \mu \mathrm{L}, 1.2 \mathrm{mmol})$ in degassed benzene $(15 \mathrm{~mL})$, the mixture of 1,3,5-triphenyl-6-oxoverdazyl radical (655 mg, $2 \mathrm{mmol}$ ) and 1-(1-bromoethyl)-4-nitrobenzene (552 $\mathrm{mg}, 2.4 \mathrm{mmol})$ in degassed benzene $(15 \mathrm{~mL})$ was added. The reaction solution was degassed again, put under argon and heated to $80{ }^{\circ} \mathrm{C}$ until full conversion of the starting material (monitored by TLC). The mixture was cooled to room temperature, filtered over celite. Mother liquid was concentrated in vacuo until minimal volume, hexane $(30 \mathrm{ml})$ was added and precipitated product was filtered and washed with hexane $(50 \mathrm{ml})$.

\section{1-(1-(4-nitrophenyl)ethyl)-2,4,6-triphenyl-1,4-dihydro-1,2,4,5-tetrazin-3(2H)-one AlkVZ 2.}

Grey solid $(812 \mathrm{mg}, 85 \%$ yield $), \mathbf{m p}=197.1-198.2{ }^{\circ} \mathrm{C}{ }^{\circ} \mathrm{C} .{ }^{1} \mathbf{H} \mathbf{~ N M R}\left(\mathrm{CDCl}_{3}, 400 \mathrm{MHz}\right)$ : two rotamers are visible in a ratio of $0.80: 0.20, \delta 1.55(\mathrm{~d}, 3 \mathrm{H}, J=7.1 \mathrm{~Hz}$, major), $1.65(\mathrm{~d}, 3 \mathrm{H}$, $J=6.9 \mathrm{~Hz}$, minor), 4.71 (q, $1 \mathrm{H}, J=7.0 \mathrm{~Hz}$, major), 7.00 (d, 2H, $J=7.6 \mathrm{~Hz}$, major), 7.10 (t, 1H, $J=7.3 \mathrm{~Hz}$, major), $7.21(\mathrm{t}, 3 \mathrm{H}, J=7.9 \mathrm{~Hz}$, major), $7.36-7.60(\mathrm{~m}, 7 \mathrm{H}), 7.85(\mathrm{~d}, 2 \mathrm{H}, J=7.8 \mathrm{~Hz}$, major), $8.02\left(\mathrm{~m}, 3 \mathrm{H}\right.$, minor), $8.09\left(\mathrm{dd}, 2 \mathrm{H}, J_{1}=2.9 \mathrm{~Hz}, J_{2}=6.5 \mathrm{~Hz}\right.$, major), 8.17 (d, $2 \mathrm{H}$, $J=8.6 \mathrm{~Hz}$, major) ppm. ${ }^{13} \mathbf{C}\left\{{ }^{1} \mathbf{H}\right\} \mathbf{N M R}\left(\mathrm{CDCl}_{3}, 101 \mathrm{MHz}\right): \delta 17.7,62.5,121.6,122.3,123.8$, $125.4,126.0,127.6,128.3,128.6,129.0,129.5,130.5,131.6,139.7,144.3,145.4,148.1,149.7$, 152.6 ppm. UV-vis $\left(\mathrm{CH}_{2} \mathrm{Cl}_{2}\right): \lambda_{\max }(\log \varepsilon)=263$ (4.16), 316 (3.49), 336 (3.45) nm. Anal. calcd. for $\mathrm{C}_{28} \mathrm{H}_{23} \mathrm{~N}_{5} \mathrm{O}_{3}: \mathrm{C}, 70.43 ; \mathrm{H}, 4.86 ; \mathrm{N}, 14.67$. Found: C, 70.34; H, 14.80; N, 14.71. 


\section{Cell culture}

A breast cancer cells (MCF-7 line) has been used as a biological object to assess the cytotoxicity of the test substance. Cells were cultured in complete growth medium DMEM (Gibco, USA) supplemented with glutamine (GlutaMAX, Gibco, USA), 10\% fetal bovine serum (One Shot ${ }^{\mathrm{TM}}$, Thermo Fisher Scientific, Brazil), antibiotics (penicillin/streptomycin mixture, Paneko, Russia) in a $\mathrm{CO}_{2}$ incubator with $5 \% \mathrm{CO}_{2}$ at $37^{\circ} \mathrm{C}$. The cells were used in the experiment in the exponential growth phase when the confluence reached approx. 70\%. Growth and morphology of the cells were controlled using optical microscope (Zeiss Axio vert A1). For the experiment, cells were seeded into a 96-well plate at concentration of 5000 cells per well. Then, the cells were adapted and adhered to the surface within 24 hours. After that, the test compounds were added to wells at the appropriate concentration, in 6 replications.

\section{Irradiation procedures}

One plate was placed in oxygen-controlled $\mathrm{CO}_{2}$ incubator with $5 \%$ of oxygen atmosphere for 2 hours for oxygen release and then was irradiated with LED for 20 minutes.

Four plates were handled in normoxia condition. One plate was loaded with preliminary irradiated (for 40 minutes) DMEM media contained $105 \mu \mathrm{M}$ of AlkVZ 2 and this plate was left non-irradiated. Three plates were irradiated with LED matrix light $\left(395-410 \mathrm{~nm}, 10 \mathrm{~mW} / \mathrm{cm}^{2}\right)$ for required time (10, 20, 40 minutes). The control plate was left non-irradiated.

All plates (both after hypoxia and normoxia conditions) were further maintained under the same conditions $\left(5 \% \mathrm{CO}_{2}, 37^{\circ} \mathrm{C}\right)$ for 24 hours.

\section{Viability assay}

The assessment of cell viability after exposure to the studied substance with and without light irradiation was carried out using the standard MTT assay. After completion of the required cultivation period, the culture medium was replaced in all wells with a medium containing 3(4,5-dimethylthiazol-2-yl)-2,5-diphenyl-2H-tetrazolium bromide (MTT reagent) at a concentration of $0.45 \mathrm{mg} / \mathrm{ml}$. Then the plates were cultured for 4 hours $\left(5 \% \mathrm{CO} 2,37^{\circ} \mathrm{C}\right)$, after which the medium was replaced with dimethyl sulfoxide (DMSO). Samples were shaken for 5 minutes and the optical density of the samples was measured at a wavelength of $570 \mathrm{~nm}$ (reference values were measured at a length of $620 \mathrm{~nm}$ ) on a Multiscan FS spectrophotometer (ThermoFisher). The cell viability was calculated as a percentage of the sample absorbance value vs. normalized absorbance value of the unirradiated control without exposure to the compound. 


\section{Section S3. NMR spectra}
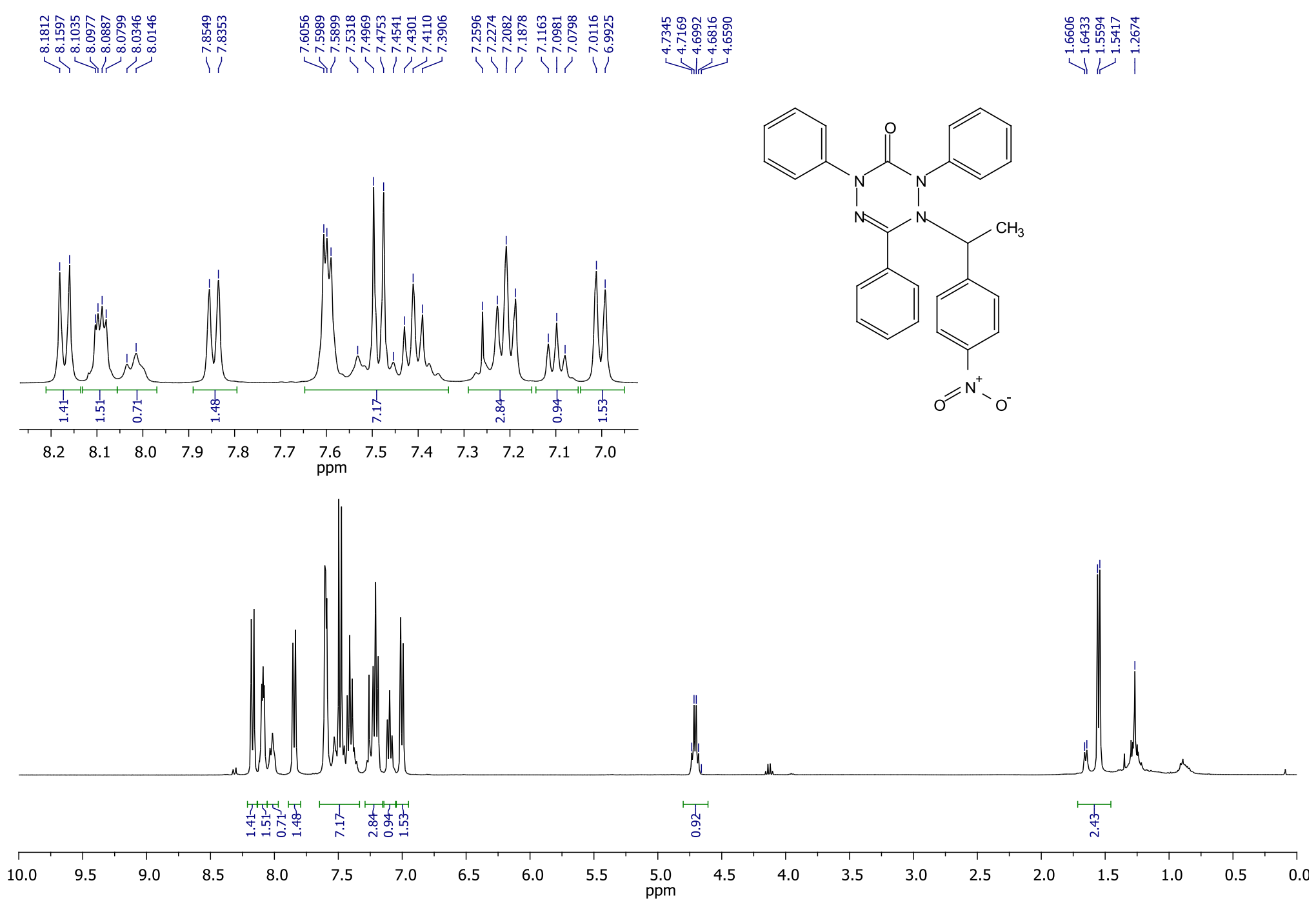

Fig. S3.1. ${ }^{1} \mathrm{H}$ NMR spectrum $\left(\mathrm{CDCl}_{3}\right)$ of 1-(1-(4-nitrophenyl)ethyl)-2,4,6-triphenyl-1,4-dihydro-1,2,4,5-tetrazin-3(2H)-one AlkVZ 2. 

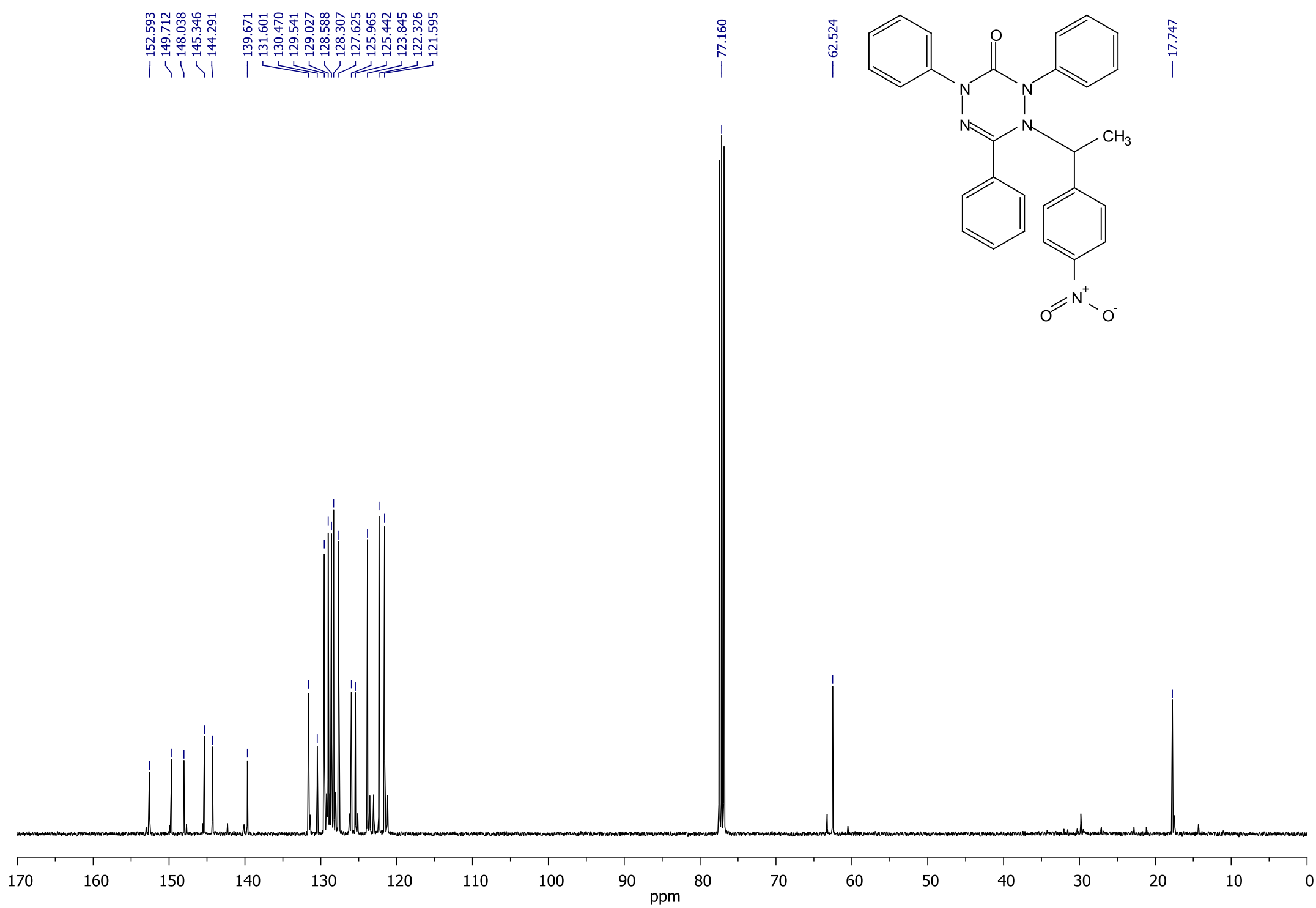

Fig. S3.2. ${ }^{13} \mathrm{C}\left\{{ }^{1} \mathrm{H}\right\}$ NMR spectrum $\left(\mathrm{CDCl}_{3}\right)$ of 1-(1-(4-nitrophenyl)ethyl)-2,4,6-triphenyl-1,4-dihydro-1,2,4,5-tetrazin-3(2H)-one AlkVZ 2. 


\section{References:}

S1 Votkina, D. E.; Petunin, P. V.; Trusova, M. E.; Postnikov, P. S.; Audran, G.; Marque, S. R.

A. Kinetic Investigation of Thermal and Photoinduced Homolysis of Alkylated Verdazyls. Phys. Chem. Chem. Phys. 2020, 22 (38), 21881-21887. https://doi.org/10.1039/d0cp03151h. 